\title{
IMMUNOLOGICAL SPECIFICITY OF HUMAN INSULIN : APPLICATION TO IMMUNOASSAY OF INSULIN
}

\author{
By ROSALYN S. YALOW AND SOLOMON A. BERSON
}

(From the Radioisotope Service, Veterans Administration Hospital, Bronx, N. Y.)

(Submitted for publication June 15, 1961 ; accepted August 30, 1961)

Previous investigations have revealed evidence for species-specificity among various mammalian insulins in immunologic reactions (1-5). For this reason, immunoassay of plasma insulin (6$10)$ in any species generally requires that the insulin employed in standard solutions be derived from the same species. Immunoassay of plasma insulin in man has been carried out by comparing the effects of unknown plasma samples with those of standard solutions of human insulin in their ability to inhibit competitively the binding of $\mathrm{I}^{\mathbf{1 3 1}}$ labeled beef insulin by guinea pig antibodies to beef insulin (7-10). Since supplies of human insulin are relatively scarce, the immunoassay of endogenous plasma insulin in man would be expedited if an animal insulin in more plentiful supply could be substituted as a standard for human insulin. Insulins from four different ungulate species (beef, hog, sheep, horse) have been found to react quantitatively with human antiserums to beef-pork insulin in a manner that could be correlated (5) with the similarity or dissimilarity of the amino acid sequences as elucidated by Harris, Sanger and Naughton (11). Of these four insulins, pork insulin (11) resembles human insulin (12) most closely in amino acid sequence, differing only in the $\mathrm{C}$-terminal residue of the $\mathrm{B}$ chain (alanine in pork insulin, threonine in human insulin). The other animal insulins differ from human insulin also in one or more of the 8 to 10 positions of the A chain. It seemed worthwhile, therefore, to examine various antiserums for similarity of reaction of pork and human insulin. The present communication describes insulin antiserums obtained from guinea pigs immunized with crystalline pork insulin that react identically with human insulin and pork insulin in respect to the competitive inhibition of binding of pork insulin$\mathrm{I}^{131}$.

\section{METHODS}

Guinea pigs were injected subcutaneously with approximately $5 \mathrm{U}$ of crystalline pork insulin (Lilly, lot no.
499667) or crystalline beef insulin (Lilly, lot no. 535664) emulsified in $0.2 \mathrm{ml}$ mannide monooleate or $10 \mathrm{U}$ of protamine zinc beef insulin (Squibb) without adjuvant at intervals of 2 to 10 weeks to a total of 4 to 7 doses. Approximately $10 \mathrm{ml}$ heparinized blood was taken by cardiac puncture about 2 weeks after insulin injections. Hypoglycemic reactions were virtually obviated by sprinkling table sugar over the chow and by adding glucose to the drinking water for 24 hours after insulin injections.

Human antiserums to insulin were obtained from insulin-resistant and nonresistant diabetic subjects treated with commercial mixtures of beef-pork insulin. Serums were taken at least 24 hours after the last injection of insulin and allowed to stand at $4^{\circ} \mathrm{C}$ for at least 8 weeks to permit destruction of any residual animal insulin by the plasma $(10,13)$.

All dilutions of antiserum and insulin were prepared in veronal buffer, ionic strength $0.1, \mathrm{pH} 8.6$, containing 0.25 per cent human serum albumin, to prevent losses of antibody or of insulin by adsorption onto glassware. When prepared as described, antiserums could be maintained at dilutions of $1: 200$ in the frozen state for many months without detectable loss of potency.

Solutions of beef and pork insulin were made from the crystalline preparations maintained in a desiccator at $4^{\circ} \mathrm{C}$ since receipt. These had been assayed at 27 to 29 $\mathrm{U}$ per $\mathrm{mg}$.

For the present study, human insulin solutions were made from two different preparations. 1) "Fisher human insulin," a dense powdery preparation, was supplied to us in 1958 by Dr. A. M. Fisher, Connaught Laboratories, Toronto. This preparation had been assayed at $6.8 \mathrm{U}$ per $\mathrm{mg}$ in 1956 but was thought possibly to have decreased slightly in hormonal potency by 1959 . Since several crystalline animal insulins obtained from Dr. Fisher were estimated at about $22 \mathrm{U}$ per $\mathrm{mg}$, we had tentatively assigned a value of $6.0 \mathrm{U}$ per $\mathrm{mg}$ to the human insulin, based on a reference standard of $22 \mathrm{U}$ per $\mathrm{mg}$ for pure insulin (10). This material was tested by immunoassay in 1959 against a preparation of human insulin, obtained from Dr. F. Tietze (through the courtesy of Dr. J. Field, $\mathrm{NIH}$, which had recently been assayed in the Lilly Research Laboratories. The assigned value of $6.0 \mathrm{U}$ per $\mathrm{mg}$ for the Fisher insulin, referred to a standard of 22 $\mathrm{U}$ per $\mathrm{mg}$ for pure insulin, agreed excellently with the recently standardized Tietze insulin and was therefore accepted as indicating an insulin content of $6.0 \mathrm{U}$ per $\mathrm{mg} /$ $22 \mathrm{U}$ per $\mathrm{mg}=27.3$ per cent insulin by weight (10). All concentrations reported here for this preparation are based 


\section{GUINEA PIG ANTI-BEEF INSULIN SERUMS}

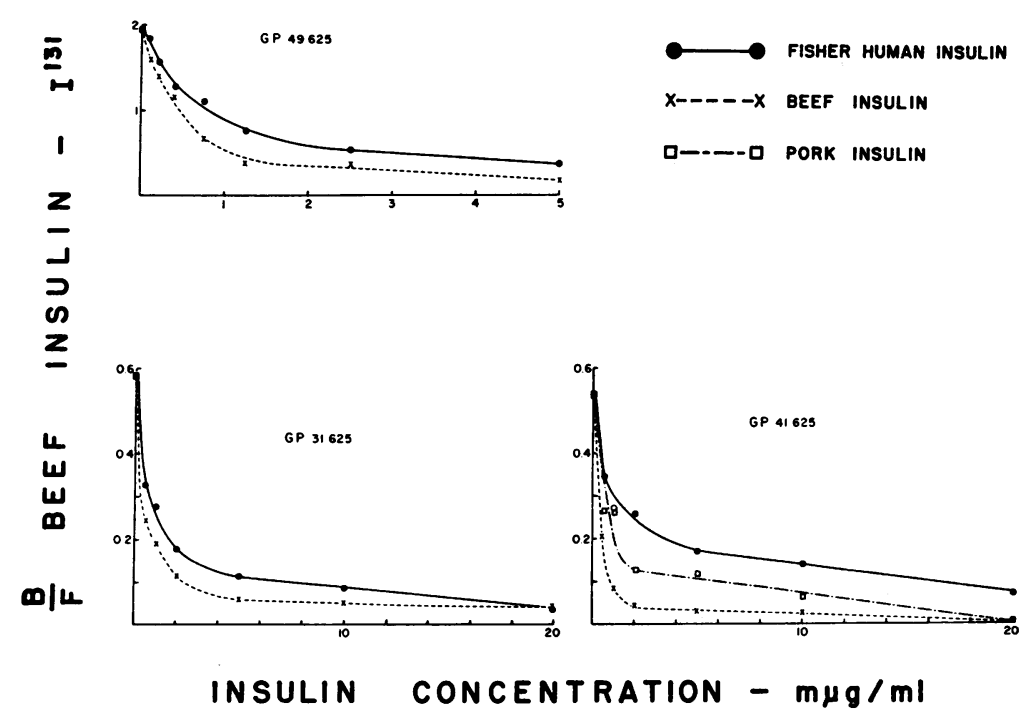

Fig. 1. RATIO OF ANTIBODY-BOUND BEEF INSULIN-I ${ }^{\text {t31 }}$ TO FREE BEEF INSULIN-I ${ }^{131}(\mathrm{~B} / \mathrm{F})$ AS A FUNCTION OF CONCENTRATION OF UNLABELED CRYSTALLINE BEEF INSULIN, CRYSTALLINE PORK INSULIN AND FISHER HUMAN INSULIN. In this and subsequent figures the insulin content of the Fisher crude powder was estimated to be 27.3 per cent by weight. Antiserum dilutions: GP 49 $625,1: 6,000$; GP 31625 and $41625,1: 4,000$.

on this value. 2) "Cambridge pure human insulin," a lyophilized preparation of pure insulin, ${ }^{1}$ was received from Dr. Ellis Samols, Royal Free Hospital, London, by courtesy of Prof. F. G. Young, Cambridge.

Insulin- $\mathrm{I}^{131}$ was prepared from crystalline beef or crystalline pork insulin as described previously (10). All insulin-antiserum mixtures in the same experiment were prepared with identical concentrations of $\mathrm{I}^{131}$-labeled insulin and antiserum (added last in all cases) but varying concentrations of unlabeled insulin as indicated. After incubation for 3 to 5 days at $4^{\circ} \mathrm{C}$, insulin-antiserum mixtures were applied to strips of Whatman $3 \mathrm{MM}$ paper for chromato-electrophoresis as described previously (10, 13). After 45 to 90 minutes, antibody-bound insulin has moved about 3 inches from the site of application (origin) whereas unbound (free) insulin remains adsorbed to the paper at the origin. After drying, the paper strips were assayed for radioactivity in an automatic strip counter. Areas under the peaks of free and bound insulin- $\mathrm{I}^{\mathrm{si}}$ were determined with a planimeter.

\section{RESULTS}

Antiserums from guinea pigs immunized with beef insulin were tested for their ability to discriminate between unlabeled beef insulin and Fisher

\footnotetext{
1 Purified on cellulose ion-exchange columns by the method of Dr. L. F. Smith, Cambridge.
}

human insulin competing against beef insulin- $\mathrm{I}^{131}$ (Figure 1). All data were obtained in a single experiment in which the same solutions of beef and human insulin were used for all antiserums. It is evident that beef insulin competed more strongly than human insulin in all antiserums and that the relative activity of beef and human insulin varied considerably among the three antiserums. The reaction of pork insulin was intermediate between that of human insulin and that of beef insulin. Depending on the antiserum tested and on the insulin concentration, it required from about 1.5 to 20 times as high a concentration of human insulin as beef insulin to reduce the ratio bound beef insulin- $\mathrm{I}^{131} /$ free beef insulin- $\mathrm{I}^{131}(\mathrm{~B} / \mathrm{F})$ to the same value. The results on guinea pig serum no. 49625 were essentially the same (with respect to the relative activities of beef and human insulin) as those reported previously in another experiment with the same antiserum (10). A somewhat larger amount of beef insulin- $\mathrm{I}^{131}$ was used in the present experiment so that the initial ratio (in the absence of added unlabeled insulin) is slightly below that obtained previously. 


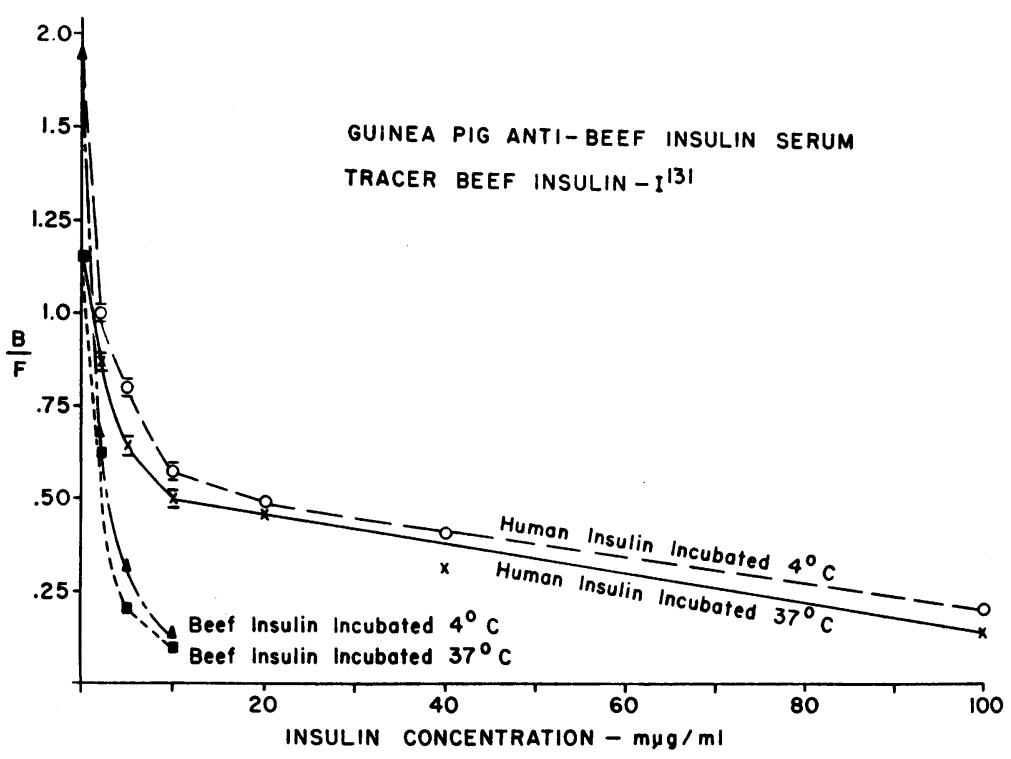

Fig. 2. Same as Figure 1. GP antiserum 10 328, dilution 1: 80.

To evaluate the influence of temperature on the difference in reactivities of beef and human insulin, another guinea pig antibeef insulin serum was studied in a separate experiment by incubation at $4^{\circ}$ and $37^{\circ} \mathrm{C}$ (Figure 2). Although the $\mathrm{B} / \mathrm{F}$ ratio at all concentrations was higher at $4^{\circ}$ than at $37^{\circ} \mathrm{C}$, as reported previously for human antise- rums (14), there was no striking difference in the relative reactivities of the two insulins at the two temperatures.

Antiserums from human subjects treated with commercial mixtures of beef-pork insulin were studied in a similar manner (Figure 3). Again, all curves are from a single experiment in which

HUMAN ANTI-BEEF, PORK INSULIN SERUMS

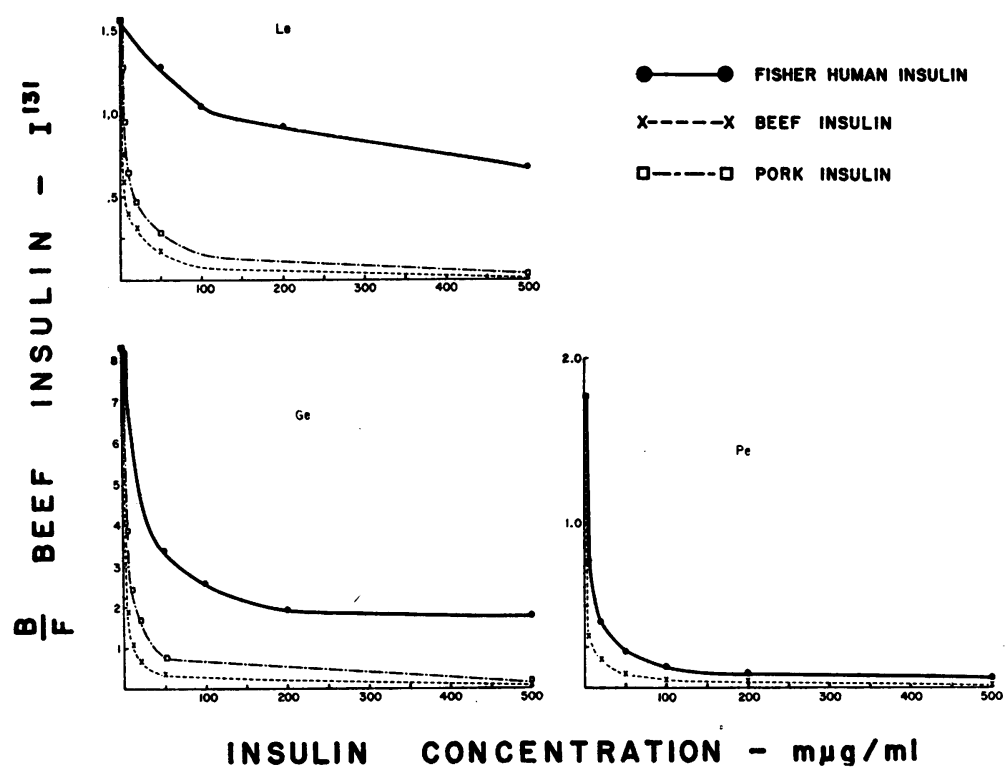

Fig. 3. SAme AS Figure 1. Antiserum dilutions: Le, $1: 60 ; \mathrm{Ge}, 1: 400$; $\mathrm{Pe}, 1: 5$. 
the same insulin solutions were employed for all antiserums. It is evident that human antiserums may discriminate even more markedly than guinea pig antiserums between beef and Fisher human insulin. The relative reactivities of beef and human insulin, respectively, varied from about 3 to 200 depending on the antiserum tested and the in sulin concentration employed. Pork insulin reacted somewhat more weakly than beef insulin but more strongly than human insulin in these antiserums.
In Figure 4 are shown results of similar studies in three guinea pig and three human antiserums in which the effects of beef insulin and the Cambridge pure human insulin are compared weight for weight in a single experiment. The same insulin solutions were employed for all antiserums. Results are similar to those of preceding experiments. In individual antiserums, the ratio between beef and human insulin concentrations required to reduce $\mathrm{B} / \mathrm{F}$ to the same value varied over as much as a fivefold range at different $B / F$ values.

\section{HUMAN ANTI-BEEF, PORK INSULIN SERUMS}

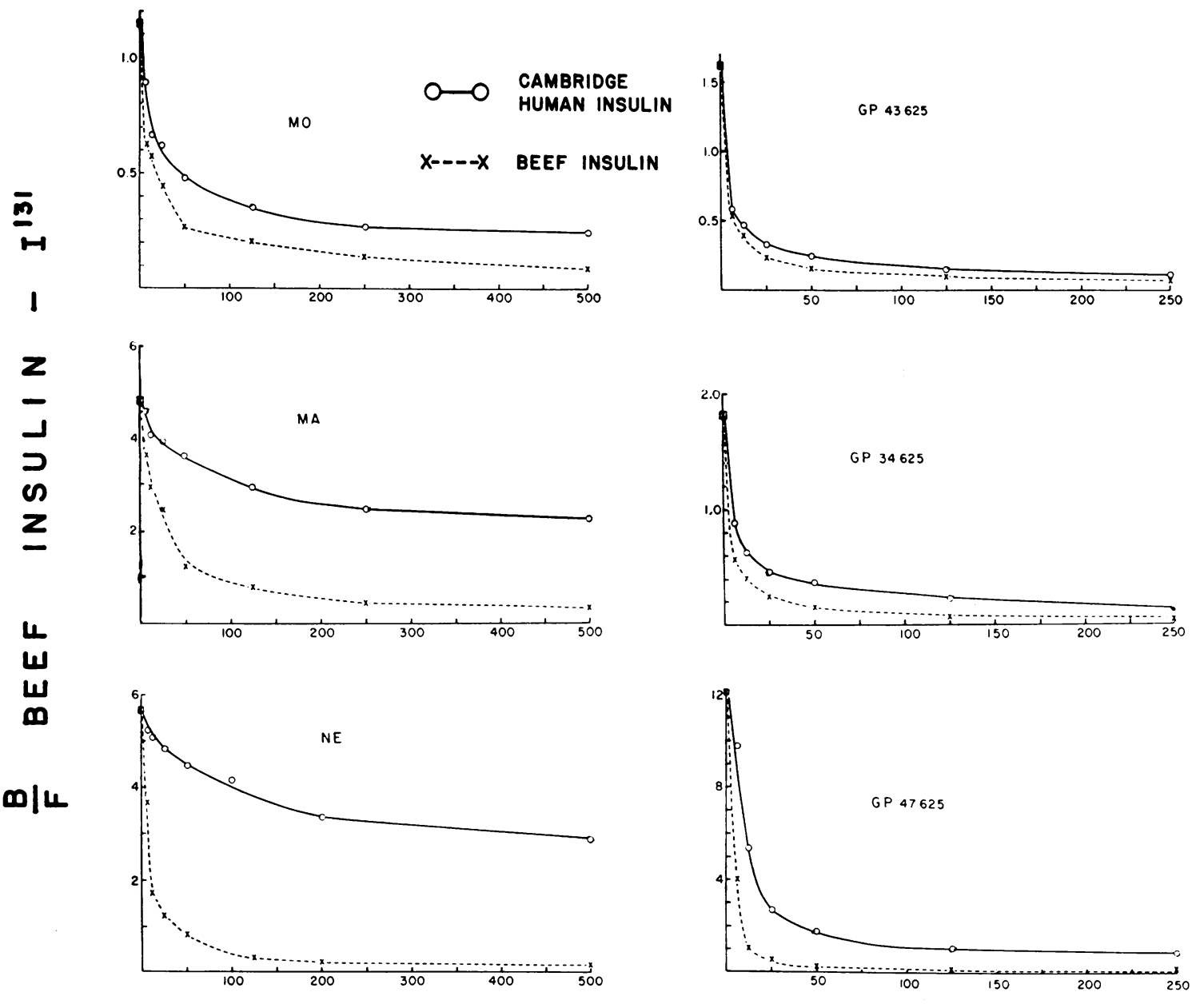

\section{INSULIN CONCENTRATION - $m \mu g / m I$}

Fíic. 4. B/F ratios for beef insulin- ${ }^{131}$ as a Function of concentration of Cambridge human insulin and CRystalline beef insulin. Antiserum dilutions: Mo and Ne, 1:20; Ma, 1:40; GP 43 625, 1:400; GP 34625 and $47625,1: 1,000$. 


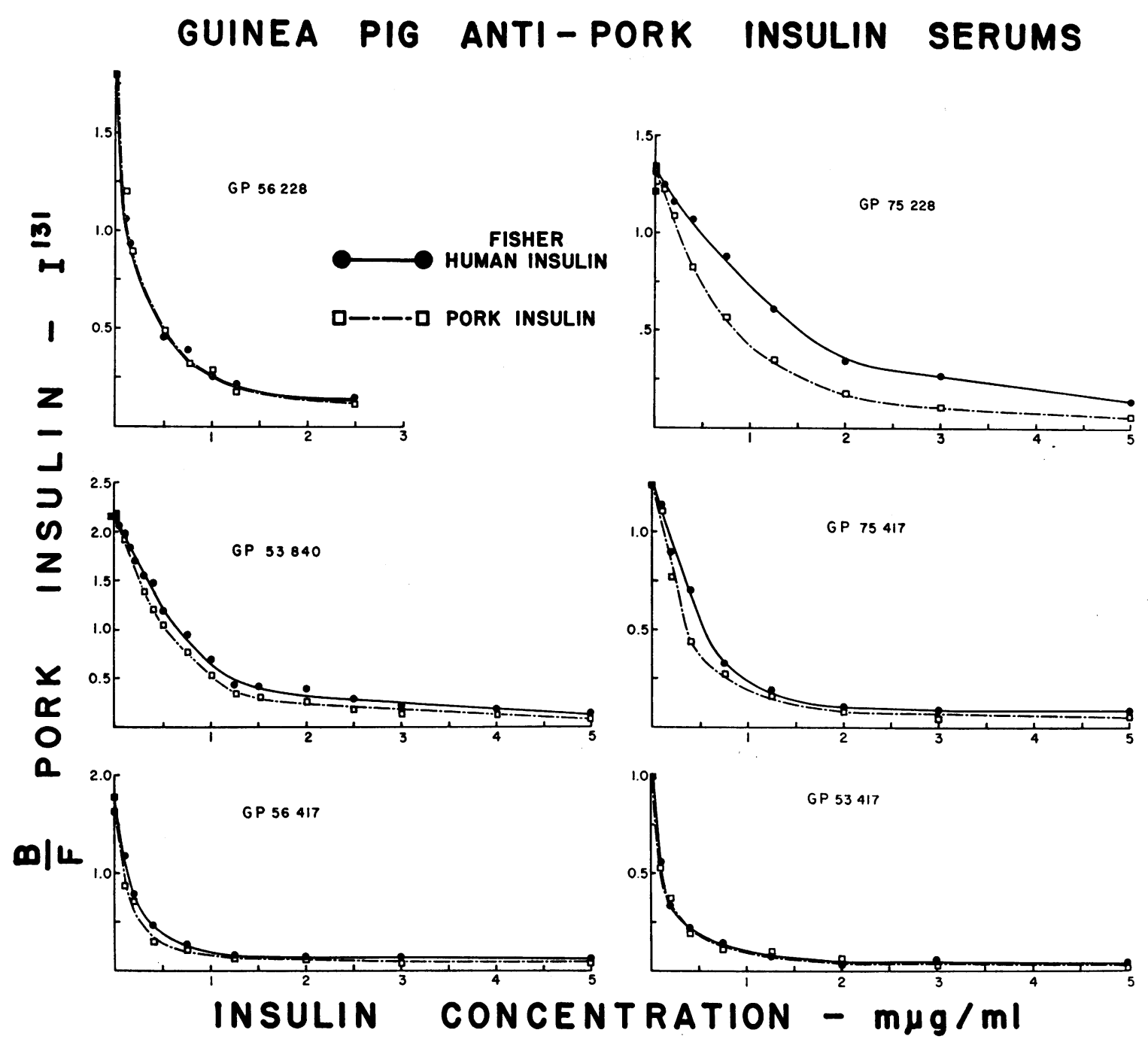

Fig. 5. B/F RATIOS FOR PORK INSULIN-I ${ }^{131}$ AS A FUNCTION OF CONCENTRATION OF FisheR HUMAN INSULIN AND CRYSTALLINE PORK INSULIN. Antiserum dilutions: $56228,1: 2,000 ; 53840,1: 8,000 ; 56417,1: 10,000 ; 75$ 228, $1: 1,500$; $75417,1: 10,000 ; 53417,1: 60,000$.

In contrast to results obtained with beef insulin- $\mathrm{I}^{131}$ in beef insulin-immunized guinea pigs, antiserums from guinea pigs immunized with pork insulin generally discriminated less readily between pork insulin and Fisher human insulin when tested against pork insulin- $\mathrm{I}^{131}$ (Figure 5). Two particular antiserums (GP no. 56228 and GP no. 53 417) showed curves identical with pork insulin and Fisher human insulin.

In Figure 6 is presented a comparison of pork insulin and Cambridge pure human insulin, weight for weight, and Fisher human insulin estimated as 27.3 per cent insulin as calculated above, all competing against pork insulin- $\mathrm{I}^{131}$ in guinea pig anti- pork insulin serum no. 53 417, earlier (Figure 5) shown to exhibit identical behavior toward pork and Fisher human insulin. It is evident that the Fisher insulin, estimated at 27.3 per cent insulin by weight, the Cambridge pure insulin and the pork insulin all react identically and that this guinea pig antiserum does not distinguish among the two samples of human insulin and the sample of pork insulin. The results of the Fisher-Cambridge insulin comparison confirm results recently obtained by Dr. Ellis Samols, London, who found the Fisher crude powder "consistently equivalent to 25 to 30 per cent Cambridge insulin by weight" (15). 


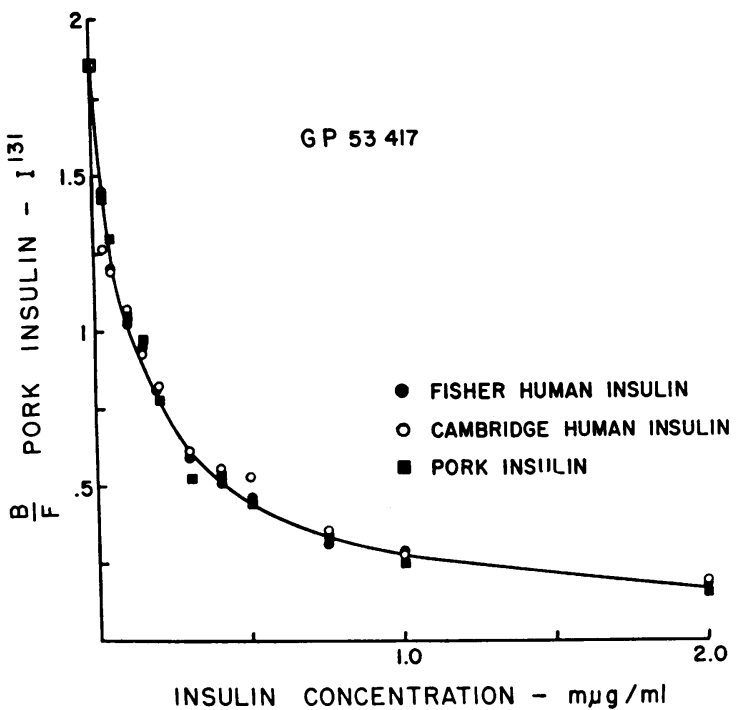

FIG. 6. B/F RATIOS FOR PORK INSULIN- ${ }^{131}$ AS A FUNCTION OF CONCENTRATION OF FISHER HUMAN INSULIN, CAMbridge human insulin aNd CRYSTALline PORK INsulin. Antiserum dilution, $1: 30,000$.

\section{DISCUSSION}

Recently, Grodsky and Forsham (16), employing a single beef-pork insulin antiserum from an insulin-resistant human subject as well as guinea pig antiserum to beef insulin, have tested various preparations of beef and human insulin (each at only two concentrations) for their ability to inhibit the binding of beef insulin- $\mathrm{I}^{131}$ to insulin antibodies. Their reported observations reveal that although a preparation of beef insulin assayed about 25 per cent higher in the human antiserum than in the guinea pig antiserum, all four preparations of human insulin assayed considerably lower in human antiserum than in guinea pig antiserum, using the same crystalline beef insulin as a reference standard for all assays. For one of the human insulin preparations, the assay in guinea pig antiserum was almost 300 per cent as high as in human antiserum, and for the other three preparations the human insulin assayed about 25 to 65 per cent higher in guinea pig than in human antiserum, as estimated from the published figure. Yet, it was concluded that "agreement between the immunoassay values for human insulin against beef insulin standards when either guinea pig or human antiserum was used was demonstrable." It is difficult to reconcile the authors' conclusion that human insulin and beef insulin react similarly in guinea pig and human insulin antiserums with the results of their studies on a single human antiserum which clearly dispute such a conclusion. "Agreement" of the order of magnitude reported hardly refutes our previous contention that beef insulin cannot be used indiscriminately as a standard for human insulin in immunologic systems (10). The more extensive data of the present study confirm previous observations that human insulin generally competes less strongly than beef insulin against the binding of beef $\mathrm{I}^{131}$-insulin in antiserums from human subjects or from guinea pigs immunized with beef insulin and that the relative reactivities of human and beef insulin may vary widely among different antiserums. Furthermore, Burrows, Peters and Lowell (4) have reported on two human antiserums in which human insulin produced either no effect or only very slight effect on the binding of beef insulin- $\mathrm{I}^{131}$ Earlier, Lowell (2) had reported that administration of human insulin to an insulin-resistant patient was effective in lowering blood sugar although beef insulin in the same dosage was completely ineffective, and Lerman (17) had emphasized that insulin antibodies in insulin-resistant human subjects are weakest when tested against human insulin. More recently we have directly compared human insulin binding (employing human insulin- $\mathrm{I}^{131}$ with unlabeled human insulin) and beef insulin binding (employing beef insulin- $\mathrm{I}^{131}$ with unlabeled beef insulin) in eight human antiserums (18). Weaker binding of human insulin than of beef insulin was observed in almost all cases. It is only to be expected that the cross reaction of unlabeled human insulin with $\mathrm{I}^{131}$-labeled beef insulin would be still weaker. The evidence of previous studies and that of the experiments reported here clearly refute the notion that beef and human insulin react similarly with human antibeef-pork insulin serums or with guinea pig antibeef insulin serums.

Grodsky and Forsham (16) also studied the Fisher preparation of human insulin, which they report as having been recently assayed in the Lilly Research Laboratories at $4.08 \mathrm{U}$ per $\mathrm{mg} .{ }^{2}$ Applying this new assay to a figure previously published by the present authors, Grodsky and Forsham concluded 1) that the beef insulin and human insulin curves could be superimposed and

\footnotetext{
2 Based on a reference standard of 27 to $29 \mathrm{U}$ per $\mathrm{mg}$.
} 
therefore that these two insulins reacted identically against beef insulin- $\mathrm{I}^{181}$ in guinea pig antibeef insulin antiserums, and 2) that the proportionality between beef and human insulin in the original data "varied only from 0.45 to 0.55 regardless of the point chosen along the curves for the calculations." However, as is evident from the reproduced figure in their paper as well as from the original data, this statement is inaccurate, since the proportionality factor ranged from about 0.3 to 0.6 . It might also be noted that the original figure showed values for the Tietze insulin falling along the same curve as the Fisher insulin, but the former were omitted from the reproduced figure. A repeat experiment with the same antiserum (GP no. 49625 ), presented in the current study (Figure 3), completely confirms the previously reported results. Thus, the same human insulin solution, if assayed at different dilutions with reference to the beef insulin curve, would have yielded estimates differing by almost 100 per cent in the antiserum reported. The results of the present study confirm and extend previous observations that the relative reactivities of human and beef insulin may vary over a range considerably greater than 100 per cent and even as great as $\mathbf{5 0 0}$ per cent at different concentrations in the same antiserum. It is evident from Figures 1-4 that no single correction factor for the Fisher human insulin concentration could possibly superimpose the curves for human and beef insulin in all antiserums.

If the Fisher insulin were significantly lower in insulin content than previously estimated, the findings of the present study would require the interpretation that human insulin reacts more strongly than pork insulin with guinea pig antibodies to pork insulin in competing with pork insulin- $\mathrm{I}^{131}$. This is a most unlikely result. It is quite possible that there has been a greater loss of hormonal potency in the Fisher insulin than previously estimated, ${ }^{3}$ particularly since a longer

3 This loss, if it does occur, need not be the same in all hands. Our supplies have been kept in a desiccator at $4^{\circ} \mathrm{C}$ since receipt in July 1959 and no diminution in immunologic reactivity has been observed to date. Among other factors, simple deliquescence can account for a significant increase in weight, thereby decreasing the potency (hormonal or immunologic) per unit weight. Furthermore, crystalline beef insulin (lot no. 535664), re- period of time has elapsed. Nevertheless, the entire insulin molecule certainly did not disappear from the powder and that part of its structure responsible for immunologic activity could remain essentially intact even if hormonal activity were abolished. Desoctapeptide beef insulin (lacking 8 amino acids from the C-terminal end of the B chain) is completely inactive hormonally (19) and yet reacts in the immunologic system (20). Therefore, loss of hormonal potency, if it has occurred, cannot necessarily be considered equivalent to a diminution in immunologic potency. By immunoassay, the Fisher insulin can certainly not be considered significantly weaker than originally estimated by us, if consideration is given to the comparisons with the Cambridge pure insulin and the crystalline pork insulin. The identity of reaction of Fisher insulin (on the basis of its previously assigned value) and Cambridge insulin (15, and present study), and the identity of reaction of Fisher human insulin and pork insulin in certain guinea pig antipork insulin serums indicate that the immunologically active insulin content of the Fisher preparation has remained essentially unchanged as estimated on the basis of its original assay of hormonal activity. It should be appreciated that unless the water content of dried insulin powders is determined precisely, an uncertainty of about 10 per cent must always exist regardless of the method of assay.

On the basis of the amino acid sequences of the various mammalian insulins $(11,12)$, it might be anticipated that human insulin would show a closer immunologic relationship to pork insulin than to other animal insulins which differ from human insulin at two sites. Previous studies had suggested that the 8 to 10 sequence of the insulin $\mathrm{A}$ chain is an important site of reaction with antibodies in the serums of human subjects immunized with beef-pork insulin mixtures (5). Even if pork insulin itself were not antigenic, the reaction of pork insulin at this site could be interpreted in the same light as the reaction of human insulin (5), namely, that antibody once formed in response to sensitization with an insulin distinctly foreign in structure at a small site can then react with other insulins differing slightly at this site.

ceived by us in 1955 , has also been used by many other workers who have relied on the original assay. 
However, aside from differences in amino acid sequences, the various insulins might well exhibit differences in secondary or tertiary structure as well, a suggestion supported by distinct immunochemical differences between sperm whale and pork insulin (21), which are reported as identical in amino acid sequences $(11,22)$. Since the structure of guinea pig insulin has not yet been elucidated, it is not possible to speculate on the potentially antigenic sites of beef and pork insulin in this species. The very close similarity (or identity) of reaction of pork and human insulin with guinea pig antibodies against pork insulin suggests that the $\mathrm{C}$-terminal end of the $\mathrm{B}$ chain might not be antigenic. That there is at least one other antigenic site is deducible from observations that desoctapeptide beef insulin reacts with guinea pig antipork insulin serums (23). However, an additional contribution of the $\mathrm{C}$-terminal residue of the $\mathrm{B}$ chain to antigenicity of pork insulin can certainly not be excluded. Furthermore, the similarity of pork and human insulin does not extend to the reaction against beef insulin- $\mathrm{I}^{131}$ (or even against pork insulin- $\mathrm{I}^{131}$ ) in beef insulin-immunized guinea pigs or humans (5). Since beef and pork insulin contain the same $\mathrm{C}$-terminal amino acid in the $\mathrm{B}$ chain, no differences in antigenicity of this group can be expected and we must again postulate structural differences beyond those of specific amino acid sequence to account for all findings. In any event, these theoretical speculations are outside the practical purpose of the present study, namely, the procurement of antiserums suitable for immunoassay of endogenous plasma insulin in man under conditions that dispense with the need for human insulin.

\section{SUMMARY AND CONCLUSIONS}

1. Previous observations of variable and occasionally marked differences in reaction of beef insulin and human insulin competing with beef insulin- $\mathrm{I}^{131}$ in human antibeef-pork insulin serums and in guinea pig antibeef insulin serums are confirmed and extended.

2. Antiserums from guinea pigs immunized with pork insulin exhibit close similarity of reaction with pork and human insulin. In two antiserums, pork and human insulin reacted identically when competing against the antibody-binding of pork insulin- $\mathrm{I}^{131}$. Employment of these antiserums for the immunoassay of endogenous plasma insulin in man obviates the necessity for employment of human insulin as a standard.

3. Human insulin (Fisher), previously estimated at 27.3 per cent insulin by weight, was assayed against pure human insulin (Cambridge) as standard. Present results confirm the accuracy of the previous estimate for immunologically active insulin content of the Fisher preparation.

\section{ACKNOWLEDGMENTS}

The authors are indebted to Drs. O. Behrens and C. W. Pettinga for crystalline beef and pork insulins, to Dr. F. Carpenter for desoctapeptide beef insulin, to Drs. F. Tietze, A. M. Fisher and E. Samols for human insulin and to Dr. Y. Ishihara for sperm whale insulin.

\section{REFERENCES}

1. Lewis, J. H. The antigenic properties of insulin. J. Amer. med. Ass. 1937, 108, 1336.

2. Lowell, F. C. Evidence for the existence of two antibodies for crystalline insulin. Proc. Soc. exp. Biol. (N. Y.) 1942, 50, 167.

3. Moloney, P. J., and Coval, M. Antigenicity of insulin: Diabetes induced by specific antibodies. Biochem. J. 1955, 59, 179.

4. Burrows, B. A., Peters, T., and Lowell, F. C. Physical binding of insulin by gamma globulins of insulin-resistant subjects. J. clin. Invest. 1957, 36, 393.

5. Berson, S. A., and Yalow, R. S. Species-specificity of human anti-beef, pork insulin serum. J. clin. Invest. 1959, 38, 2017.

6. Berson, S. A., and Yalow, R. S. Isotopic tracers in the study of diabetes. Advanc. biol med. Phys. 1958, 6, 349.

7. Berson, S. A., and Yalow, R. S. Recent studies on insulin-binding antibodies. Ann. N. Y. Acad. Sci. 1959, 82, 338.

8. Yalow, R. S., and Berson, S. A. Assay of plasma insulin in human subjects by immunological methods. Nature (Lond.) 1959, 184, 1648.

9. Yalow, R. S., and Berson, S. A. Plasma insulin concentrations in nondiabetic and early diabetic subjects. Determinations by a new sensitive immunoassay technic. Diabetes 1960, 9, 254.

10. Yalow, R. S., and Berson, S. A. Immunoassay of endogenous plasma insulin in man. J. clin. Invest. 1960, 39, 1157.

11. Harris, J. I., Sanger, F., and Naughton, M. A. Species differences in insulin. Arch. Biochem. 1956, $65,427$.

12. Nicol, D. S. H. W., and Smith, L. F. Amino-acid sequence of human insulin. Nature (Lond.) 1960 , 187, 483. 
13. Berson, S. A., Yalow, R. S., Bauman, A., Rothschild, M. A., and Newerly, K. Insulin- $\mathrm{I}^{131}$ metabolism in human subjects: Demonstration of insulin-binding globulin in the circulation of insulin treated subjects. J. clin. Invest. 1956, 35, 170.

14. Berson, S. A., and Yalow, R. S. Quantitative aspects of reaction between insulin and insulin-binding antibody. J. clin. Invest. 1959, 38, 1996.

15. Samols, E. Personal communication.

16. Grodsky, G. H., and Forsham, P. H. Comparative binding of beef and human insulin to insulin antibodies produced in man and guinea pigs. J. clin. Invest. 1961, 40, 799.

17. Lerman, J. in Discussion of Smelo, L. S. Diabetes 1948, 8, 107.

18. Berson, S. A., and Yalow, R. S. Preparation and purification of human insulin- $\mathrm{I}^{131}$; binding to hu- man insulin-binding antibodies. J. clin. Invest. 1961, 40, 1803.

19. Carpenter, F. H., and Young, J. D. Isolation of desoctapeptide insulin. Fed. Proc. 1959, 18, 201.

20. Berson, S. A., and Yalow, R. S. Immunologic aspects of insulin. Amer. J. Med. 1961, 31, 882.

21. Berson, S. A., and Yalow, R. S. Immunochemical distinction between insulins with identical amino acid sequences from different mammalian species (pork and sperm whale insulins). Nature (Lond.) 1961, 191, 1392.

22. Ishihara, Y., Saito, T., Ito, Y., and Fujino, M. Structure of sperm- and sei-whale insulins and their breakdown by whale pepsin. Nature (Lond.) 1958, 181, 1468.

23. Berson, S. A., and Yalow, R. S. Unpublished observations. 